\title{
Teoria Organizacional numa perspectiva crítica na formação de Sanitaristas para a Gestão em Saúde Coletiva
}

\author{
Maria Clara Vieira Weiss ${ }^{1 *}$ \\ Universidade Federal de Mato Grosso, Instituto de Saúde Coletiva, Cuiabá - MT, Brasil \\ Ruth Terezinha Kehrig', \\ Universidade Federal de Mato Grosso, Instituto de Saúde Coletiva, Cuiabá - MT, Brasil
}

\begin{abstract}
Recebido em 25 de Julho de 2016. Aceito em 17 de Setembro de 2016
\section{RESUMO}

O artigo tem por objetivo apresentar uma experiência teórico-prática no ensino das teorias organizacionais na formação de bacharéis em Saúde Coletiva. A resposta à questão - de que introdução às teorias das organizações o Sanitarista precisa em sua formação -, no contexto de um sistema universal de saúde e de proteção dos direitos sociais, implica uma aproximação ao pensamento crítico na grade curricular da disciplina, para pautar o aprendizado de uma administração política voltada para as transformações sociais e mudanças organizacionais dos serviços de saúde. O conteúdo programático da disciplina propicia discussões temáticas utilizando conceitos como liderança; autogestão, etnografia crítica, práticas organizacionais verticais e horizontais, modelos de gestão gerencial e societal, e a perspectiva histórica e multidimensional nas análises das organizações. Essas reflexões contribuem no fortalecimento dos processos de democratização da gestão das políticas públicas, na organização dos serviços públicos e na reconstrução das expressões da área de Política, Planejamento e Gestão em Saúde no campo de conhecimentos e práticas da Saúde Coletiva. Inclusive, por coerência com o referencial epistemológico do próprio campo da Saúde Coletiva.
\end{abstract}

Palavras-chave: Organização e Administração; Administração em Saúde; Gestão em Saúde

\begin{abstract}
The article aims to present a theoretical and practical experience in the teaching of organizational theories in bachelors training in Public Health. The answer to the question - that introduction to the theories of the organizations Sanitarian need in their training - in the context of a universal system of health and protection of social rights, requires an approach to critical thinking in the curriculum of the course, to steer the learning a policy management for social change and organizational changes in the health services. The syllabus of the course provides thematic discussions using concepts such as leadership; self-management, critical ethnography, vertical and horizontal organizational practices, managerial and societal management models, and historical and multidimensional perspective in the analysis of organizations. These reflections contribute in strengthening the democratization process of the management of public policies, the organization of public services and the reconstruction of the terms of the policy area, Health Planning and Management in the field of knowledge and practices of Public Health. Including, for consistency with the epistemological framework of the own field of Public Health.
\end{abstract}

Keywords: Organization and Administration; Health Administration; Health Management

Agradecimentos: Aos professores substitutos Fabiano Tonaco Borges, Sergio Camargo e Aisllan Palomar que contribuíram com as discussões no decorrer da disciplina em diferentes períodos.

1- Doutora em Ciências pela ENSP/FIOCRUZ. Professora Titular da Universidade Federal de Mato Grosso, Instituto de Saúde Coletiva.

2- Doutora em Saúde Pública pela USP. Professora Adjunta da Universidade Federal de Mato Grosso, Instituto de Saúde Coletiva.

* Autor para correspondências. Maria Clara Vieira Weiss

e-mail: mcweiss@cpd.ufmt.br 


\section{Introdução}

O texto trata de uma experiência de ensino das teorias organizacionais na graduação em Saúde Coletiva que incorpora o pensamento crítico em seu referencial. A opção por uma teoria organizacional numa abordagem crítica enquanto fundamento para a gestão em Saúde Coletiva vem contribuir com a formação de Sanitaristas para a análise e transformação das organizações e dos serviços de saúde, aproximando-se de uma epistemologia da administração pública, de forma coerente com a epistemologia da constituição do campo de conhecimentos e práticas da Saúde Coletiva.

A formação de Sanitaristas enquanto bacharéis em Saúde Coletiva é uma realidade que vem acontecendo no Brasil nos últimos anos. Em 2014 havia dezessete cursos em funcionamento em todas as regiões do país, dos quais dezesseis em universidades públicas, sendo dez federais e seis em universidades estaduais, e um curso em universidade privada (FGSC/Abrasco, 2014).

Os Cursos de Graduação em Saúde Coletiva (CGSC) visam formar profissionais focados nas principais necessidades em saúde da população brasileira e no Sistema Único de Saúde. Os Sanitaristas se auto-definem como uma nova força mobilizadora do processo de Reforma Sanitária Brasileira, comprometidos com os princípios e valores éticos e políticos que inspiram tal Reforma (CASTELLANOS et al., 2013).

A denominação dos cursos de graduação em Saúde Coletiva no Brasil foi tributária da constituição do campo científico e de práticas da Saúde Coletiva vinculado ao processo da Reforma Sanitária Brasileira. O campo de conhecimento da Saúde Coletiva foi constituído a partir do movimento internacional da Medicina Social na Europa de 1848. Os estudos brasileiros de Donnangelo e Pereira (1976) e de Arouca (2003) foram precursores no pensar sobre um novo campo paradigmático para a Saúde Pública. O objeto da Saúde Coletiva "[...] compreende a investigação dos determinantes da produção social das doenças e da organização dos serviços de saúde, e o estudo da historicidade do saber e das práticas sobre os mesmos" (PAIM, 1982, apud PAIM; ALMEIDA F ${ }^{\circ}$ 2000, p.61).

O arcabouço teórico-conceitual e epistemológico da Saúde Coletiva e os desafios da Reforma Sanitária e do Sistema Único de Saúde (SUS) compõem a base argumentativa da formação do bacharel em Saúde Coletiva (BOSI; PAIM, 2010). O profissional Sanitarista tem sua formação no Brasil ancorada nas três áreas que compõe o campo científico e âmbito das práticas da Saúde Coletiva: Ciências Sociais e Humanas em Saúde; Epidemiologia; e, Política, Planejamento e Gestão de Saúde. Assim, também nessa última área do campo, onde se inserem as teorias organizacionais, a aplicabilidade do conhecimento administrativo na formação do sanitarista considerou o campo de práticas e de conhecimento da Saúde Coletiva, que é delimitado como campo de conhecimento a partir da matriz teórico-conceitual do Movimento Sanitário (NUNES, 2014), na perspectiva de formação de intelectuais orgânicos (GRAMSCI, 1982) e produção de conhecimentos inerentes à Reforma Sanitária e à implantação do SUS, promulgado na Constituição Brasileira (BRASIL, 1988).

Os pressupostos doutrinários do direito democrático de cidadania à saúde, com garantia do acesso universal e igualitário, e a integralidade da atenção prestada conforme necessidades da população, implicaram uma política de Estado para a saúde e um conjunto de iniciativas no âmbito das instituições, serviços de saúde e grupos sociais.

A fundamentação dos processos de municipalização e descentralização, voltados para a adoção de modelos assistenciais, de planejamento e gestão alternativos no referencial teórico da filosofia da práxis dialógica, plural e comunicativa -, baseada em Gramsci e Habermas, evitaria apenas a conexão política e que o "otimismo da prática" não caísse no idealismo ou no voluntarismo (FLEURY, 1997).

Entretanto, a descentralização foi uma das únicas propostas da Reforma Sanitária Brasileira que não encontrou resistência no contexto das políticas neoliberais das décadas de 1980 e 1990, uma vez que a descentralização vinha ao encontro da redução do aparelho de Estado. Tanto foi assim que a descentralização fez parte do acordo da frente municipalista da saúde com o centrão - força política de direita majoritária na Assembleia Constituinte de 1986 a 1988 - (KEHRIG et al., 2014).

Teoria Organizacional numa Perspectiva Crítica na Formação de Sanitaristas para a Gestão em Saúde Coletiva Maria Clara Vieira Weiss, Ruth Terezinha Kehrig, Giovanna Fonseca Demonti e

Angela Serafim Godinho Espíndula 
A configuração do campo de atenção à saúde a partir da produção social dos conceitos de direito e descentralização (MISOCZKY, 2002) nos apontou a necessidade de maior aprofundamento e possibilidades epistemológicas nas abordagens da área de políticas, planejamento e gestão em saúde para a formação do Sanitarista nos cursos de graduação, a partir de intercâmbios da pós-graduação em Saúde Coletiva, em particular, pesquisas numa perspectiva de avaliação construtivista interpretativista, particularmente na temática da gestão em saúde indígena (MISOCZKY, 2005; WEISS; BORDIN, 2013).

O trabalho tem por objetivo apresentar uma experiência teórico-prática no ensino das teorias organizacionais para a formação de Sanitaristas, ao pretender propiciar nesse perfil profissional a análise crítica e transformação das práticas gestoras em Saúde Coletiva.

\section{Cenário Inicial}

O Instituto de Saúde Coletiva da Universidade Federal de Mato Grosso (ISC/UFMT) iniciou seu curso de graduação em Saúde Coletiva no ano de 2010. Em sua grade curricular consta a disciplina "Introdução às Teorias Organizacionais", ofertada no segundo semestre.

O projeto pedagógico do curso de graduação em Saúde Coletiva da UFMT desenhou a ementa da disciplina que trabalha com uma introdução às teorias das organizações no Curso, contemplando: para além dos principais componentes internos de uma organização - objetivos, tecnologia, divisão do trabalho, estrutura, poder, informação, cultura, etc. - e das conceituações e inserções na sociedade das teorias das organizações, também as mudanças organizacionais - determinantes, consequências, estratégias de reação, manutenção e mudanças, e o papel do gestor -; cultura administrativa no Brasil, especificidades do setor público e privado das organizações; e, a complexidade das organizações de saúde (ISC/UFMT, 2010).

A questão colocada foi: de que introdução às teorias das organizações precisa em sua formação o Sanitarista? Essa disciplina no seu início programada com 108 horas-aulas (sendo dois terços de aulas teóricas e um terço de práticas), responde pela fundamentação teórica para as disciplinas mais gerenciais dos próximos semestres: organização do sistema de saúde, planejamento de saúde, gestão de sistemas e serviços de saúde, gestão de processos e gestão do trabalho.

Ressaltamos o compromisso com a cidadania na formação do Sanitarista, um profissional com perfil de ser capaz de conhecer e intervir sobre os problemas/situações de saúde-doença mais prevalentes, com ênfase na sua região de atuação, identificando as dimensões políticas, sociais, culturais e históricas de seus determinantes, como também ser promotor da saúde integral do ser humano (ISC/UFMT, 2010).

Considerando que a realização de ações de saúde, enquanto respostas sociais à população, dá-se no espaço organizacional onde operam os sujeitos da ação, Kehrig (2001) aproxima-se de alguns autores que contribuem na abordagem desse espaço: o modelo burocrático de Weber (1978), a sua crítica por Shon (1971) que com Pinchot e Pinchot (1995) se atrevem a falar do fim da burocracia; as organizações profissionais de Pettigrew (1992); as estratégias organizacionais de Mintzberg et al. (2000; 2006); a teoria antropológica das organizações de Chanlat (1996); e as organizações que aprendem de Senge (2000). Ainda destacamos alguns pensadores organizacionais que seguimos dentro do próprio campo da Saúde Coletiva (MENDES-GONÇALVES, 1992; TESTA, 1994; MATUS, 1993; URIBE, 2006; PAIM, 2008).

Teixeira et al. (2014) em uma revisão de literatura sobre as produções da área de Políticas, Planejamento e Gestão de Saúde identificam um conjunto heterogêneo de matrizes teóricas, predominando uma conexão com os problemas e desafios nos âmbitos político e institucional do SUS e Reforma Sanitária.

O ensino das teorias das organizações faz parte dos cursos de graduação em Saúde Coletiva criados na última década no país, até então somente abordado nos cursos de pósgraduação lato e stricto sensu. Inserida na área de Políticas e Gestão em Saúde essa disciplina no ISC/UFMT ancorou-se na interlocução com as Ciências Sociais e Humanas, o que na presente elaboração teórico-empírica foi favorecida pela experiência de docentes do campo da Administração Pública, mais especificamente da Gestão de Políticas Públicas, com formação tanto nas Ciências Sociais quanto em Administração.

A configuração docente construída para tratar dos fundamentos das organizações no processo de formação do bacharel em Saúde Coletiva conjugou uma trajetória de ensino e práticas da Administração Pública no contexto da Saúde Coletiva e reelaborou contribuições resultantes de intercambio 
interinstitucional com dois programas de pós-graduação em Administração, reconhecidos nacional e internacionalmente (via pós-doutoramentos e do Programa de Apoio Acadêmico - PROCAD/CAPES).

Desde a concepção da disciplina de Introdução às Teorias das Organizações na UFMT, por aproximações sucessivas, foram introduzidos no seu conteúdo programático conceitos e temáticas do pensamento crítico das organizações. No âmbito dessa disciplina, tem-se por objetivo propiciar uma formação do profissional Sanitarista para análise e atuação na organização dos serviços de saúde considerando as reflexões sobre uma sociologia crítica para a administração pública, e ao mesmo tempo buscando superar a limitação das abordagens clássicas, comportamentais, neoclássicas e sistêmicocontingenciais próprias da Administração. Tal opção é uma questão de coerência com o próprio campo da Saúde Coletiva.

\section{Sobre os conteúdos trabalhados na Introdução às Teorias das Organizações}

$\mathrm{Na}$ perspectiva de uma práxis das teorias organizacionais enquanto fundamento para refletir sobre as práticas gestoras nas organizações de saúde, a disciplina foi estruturada em temas: 1) os primórdios, o contexto socioeconômico na "modernidade" e o surgimento da administração; 2) o movimento da "administração científica" e escolas clássicas; 3) abordagens humanistas da administração; 4) abordagens estruturalistas das organizações; 5) abordagens sistêmico-contingenciais e neoclássicas; 6) abordagens póscontingenciais e a gestão pública; 7) atividade prática e produção criativa.

A partir de uma imersão no túnel do tempo das teorias organizacionais, destaca-se no contexto socioeconômico na "modernidade" (MOTTA; VASCONCELOS, 2010) os movimentos sociais do século 19 informados por socialistas utópicos (Saint-Simon, Blanc e Proudhon) e pelo materialismo histórico (Marx).

Com esses antecedentes abre-se o contexto de surgimento das teorias organizacionais que se constituem epistemologicamente articuladas a diferentes correntes sociológicas.

\section{Esquema gráfico de las diferentes corrientes de la Teoría Sociológica}

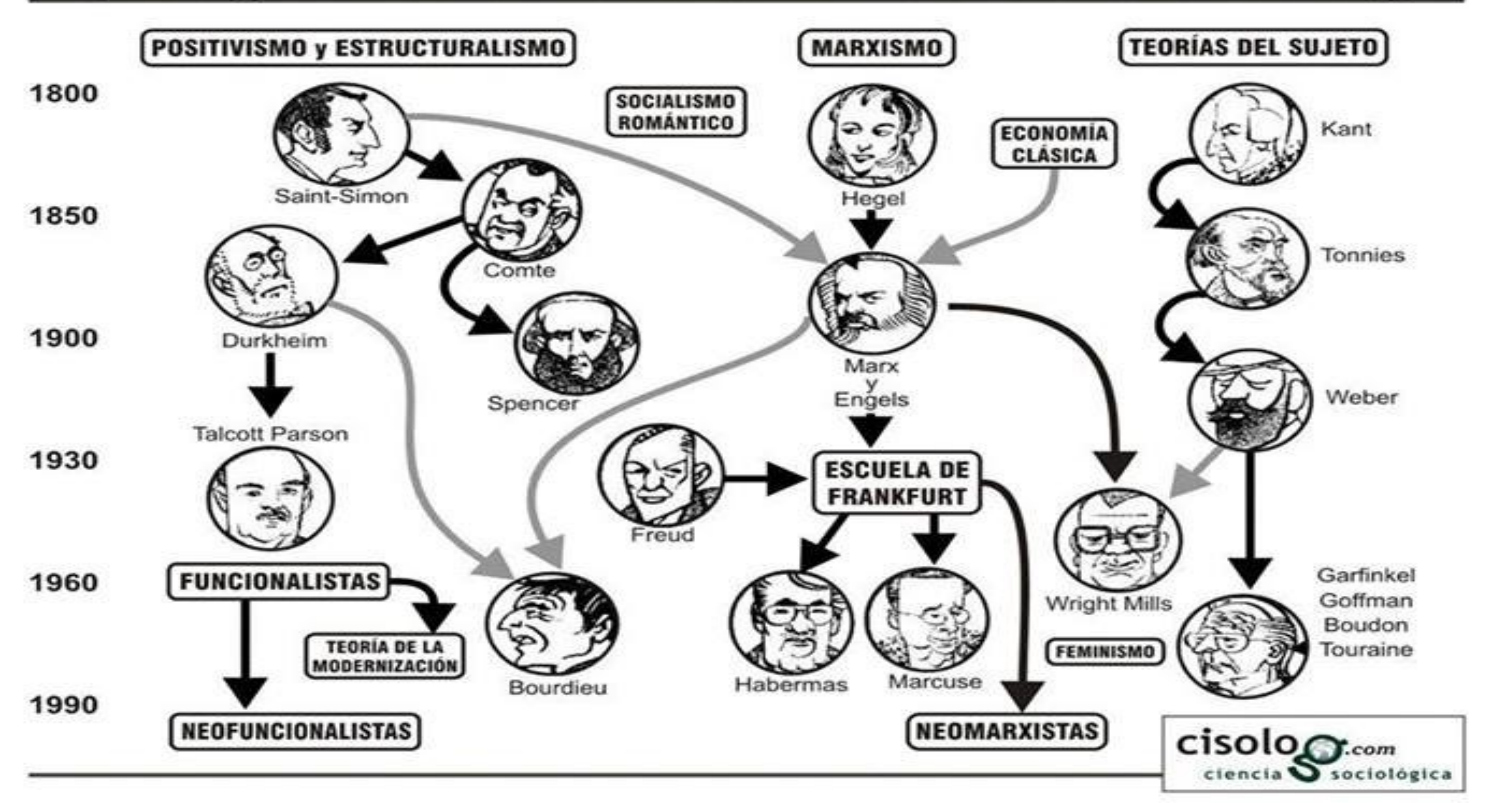

Ilustração 1 - Correntes sociológicas de referência para as teorias organizacionais. 
FONTE: CISOLOG - Ciência Sociológica, 2012. Disponível em:

$<$ http://cisolog.com/sociologia/esquema-grafico-de-las-diferentes-corrientes-en-teoria-sociologica/>.

As influências das correntes de pensamento informam a construção das teorias organizacionais. As teorias clássicas, comportamentais, estruturalistas e neoclássicas se inserem na corrente positivista e estruturalista. As teorias sistêmicas e contingenciais transitam entre a fenomenologia e a complexidade. Dentre as abordagens pós-contigenciais, o poder nas organizações direciona um movimento de reencontro com a teoria crítica na perspectiva de emancipação dos sujeitos.

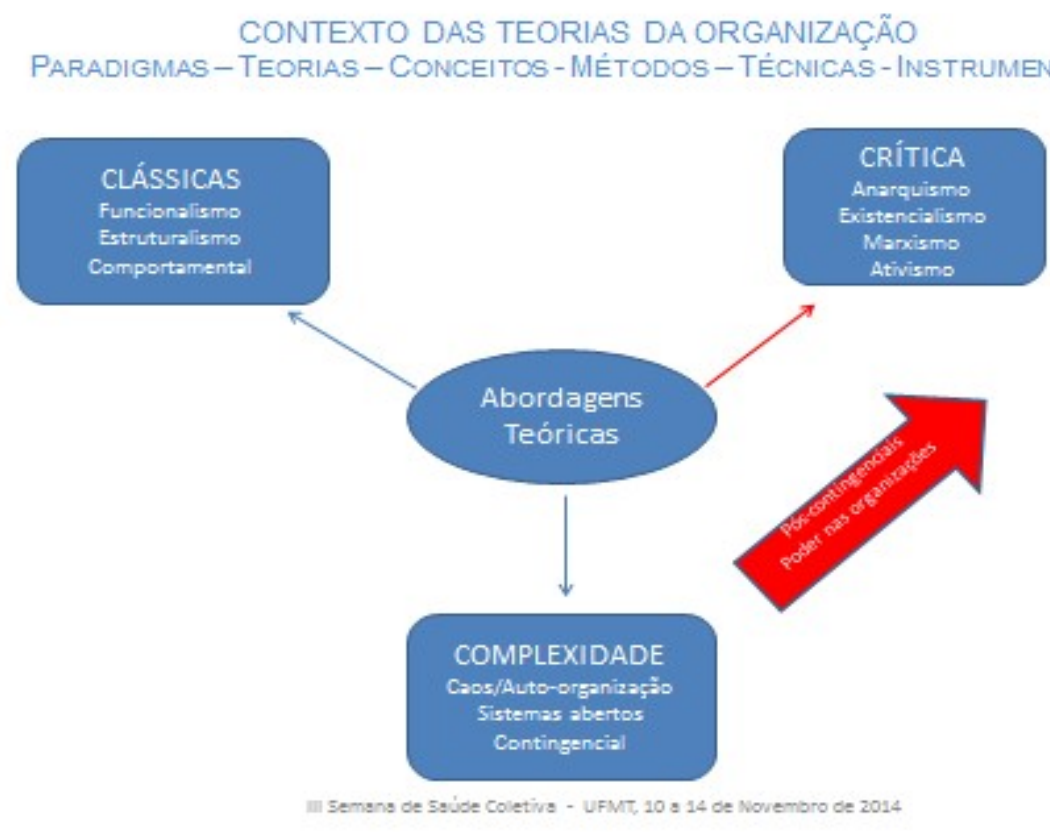

Ilustração 2 - Inserção das teorias das organizações nas principais correntes de pensamento

Em sua preocupação dialética com a construção social da experiência a teoria crítica (KINCHELOE, J.L.; MCLAREN, P., 2007, p.283)

[...] preocupa-se particularmente com as questões relacionadas ao poder e a justiça e com os modos pelos quais a economia, [...] a raça, a classe e o gênero, as ideologias, os discursos, a educação, a religião e outras instituições sociais e dinâmicas culturais interagem para construir um sistema social.

No desenvolvimento da disciplina adotou-se o percurso cronológico das teorias organizacionais durante o século 20. Em cada contexto histórico, diferentes teorias organizacionais foram elaboradas, ancoradas em diferentes concepções de homem - homo economicus, homo social, homem organizacional, homem funcional e homem complexo -, essa última concepção se aperfeiçoa no sentido da construção social da realidade (MOTTA; VASCONCELOS, 2010); concepções de organização como máquina, produtiva, espaço político e cultural, organização ativa, que constrói seu ambiente (MORGAN, 1996) e concepção de sociedade implicada.

O processo gerencial nas organizações se constitui nas ações de planejar o futuro desejado, compor os arranjos necessários de estrutura e recursos, dirigir/liderar as pessoas e controlar/avaliar as ações realizadas. Na área das ciências sociais aplicadas esta concepção gestora está fundamentada na definição de administração formulada em 1916 por Henri Fayol, engenheiro francês contemporâneo dos americanos Taylor e Ford, que compuseram a escola clássica da administração.

A opressão do trabalhador no taylorismo e fordismo do capitalismo industrial, bem ilustrada no clássico filme Tempos Modernos de Charles Chaplini impôs reflexões conceituais sobre a emancipação do homem no trabalho, autonomia e burguesia, fundamentadas no drama burguês ${ }^{i i}$. 
A primeira mulher a se expressar naquele contexto das abordagens clássicas dos engenheiros precursores da administração da teoria da administração, em uma publicação de 1920 Mary Parker Follett categoriza as relações entre patrões e empregados em três formas - a coação, coopção ou negociação, defendendo essa última como gerencialmente mais eficaz. Ao reconhecer as diferenças Follett buscava descobrir soluções negociadas e cooperativas trazendo para a administração a noção de "poder-com" ao invés de "poder-sobre". Defendia uma administração democrática ainda nos anos 20 (GRAHAM, 1997).

A participação no interior das organizações ocorre em diferentes graus e níveis, em âmbito mais técnico ou administrativo, de forma direta ou indireta, incluindo ou não decisões econômicas e políticas. Surge nas organizações como meio de trato com o conflito capital/trabalho. Na mesma década (1920) em que se evidenciavam os movimentos políticos que formaram a social democracia européia, o discurso do sindicalismo alemão debatia inclusive o que produzir e de que modo, e foram criadas as comissões de empresas com representação dos operários, surgindo a co-gestão empresarial e em alguns casos mais raros chegando a experiências de autogestão. Os esforços autogestionários são tensionados por consciência política e competência técnica e organizacional (MOTTA, 1984).

Na perspectiva de uma outra Economia, para Albuquerque (2003) a autogestão em sentido lato é um conjunto de práticas sociais que se caracteriza pela natureza democrática da decisão, propiciando a autonomia de um coletivo: qualifica as relações sociais de cooperação entre pessoas e/ou grupos, independente do tipo das estruturas organizativas ou das atividades, expressando relações sociais mais horizontais.

Ainda, na primeira metade do século passado pode-se apreender um movimento humanista na constituição das teorias organizacionais, que se colocou como contraponto ao mecanicismo dos processos produtivos industriais típicos da visão das escolas clássicas da administração. Os precursores das relações humanas nas organizações foram seguidos por psicólogos de formação behaviorista, que desenvolveram as teorias de motivação e liderança formando a abordagem comportamental da administração. Com essas contribuições, ressalvadas as críticas de manipulação e exploração "mais gentil" dos trabalhadores, a concepção gestora substitui a idéia de comando por liderança na direção das pessoas dentro das organizações.

Na abordagem comportamental, a discussão sobre a diferença entre adaptação no behaviorismo e o empoderamento dos sujeitos, segundo Paulo Freire, trouxe uma importante contribuição epistemológica a disciplina dada as aproximações de Freire com a concepção pedagógica de Vygotsky, adotada no Curso de Graduação em Saúde Coletiva. Ambos foram engajados com o seu mundo, o seu tempo e a sua realidade, preocupavam-se com os problemas que afetavam a população: a fome, a miséria, as injustiças, a opressão. A argumentação que Freire e Vygotsky utilizam para explicar a intervenção do homem sobre a natureza e consequentemente a sua transformação, fundamenta-se na categoria do trabalho utilizada por Marx através da transformação dos diferentes níveis de consciência política ou pelo desenvolvimento cultural da inteligência, respectivamente (MOURA, 2015).

Essas reflexões foram importantes na fundamentação da liderança como essencial na transformação das organizações. Entendida por Sievers (1997) como administração do sentido ou da significação, trata da maturidade da pessoa em sua capacidade de relacionar seu mundo interior e o mundo externo e a realidade dos outros, com o objetivo de realizar uma tarefa comum (passado/presente/futuro). Atribui significado sobre por que realizar as ações humanas, rompendo com a cultura da dependência nas organizações. Assim, a habitual forma de controle não é mais concebível. Para Bergamini (1994), a liderança reside em perceber como se configura o mundo à volta de cada um, o que permite construir um sentimento de identidade, satisfação e competência, o que potencializa as condições pessoais para lidar com o conflito.

Das críticas ao modelo burocrático de dominação, autoridade e controle, explicitado por Weber (1978) como compreensão da lógica das organizações, teóricos organizacionais passam a constituir a maturidade científica do pensamento administrativo e organizacional, reconhecendo os conflitos como 
expressão do conflito social entre capital e trabalho, desenhando lógicas pós-burocráticas para pensar processos organizacionais, alguns atrevendose a falar no fim da burocracia (SHON, 1971). Nessa perspectiva o controle cede lugar à avaliação.

Peter Blau (apud MOTTA; VASCONCELOS, 2010) também identificou diversas disfunções burocráticas. Esse autor destaca-se por considerar os conflitos centrais no desenvolvimento das organizações entendidas como um processo fundamentalmente dialético. Assim Blau passa a ser o primeiro teórico da administração que assume como referencial o estruturalismo dialético, mas dialogando com Weber. Nesse sentido entende o conflito organizacional como uma expressão fenomenológica de um conflito maior existente na sociedade - o conflito capital/trabalho.

Na primeira metade do século 20 as teorias foram privilegiando uma ou outra variável passando das tarefas à estrutura e dessas às pessoas. A continuidade de estudos estruturais foi incorporando as demais variáveis organizacionais, rompendo o pensamento administrativo com as visões parciais e segmentadas. A abrangência do estudo das organizações tem sido gradativamente crescente, avançando seu conteúdo dos métodos e processo de trabalho de cada operário/servidor inicialmente até chegar ao seu todo e inclusive ao contexto ambiental em que se insere a organização.

Da teoria geral dos sistemas formulada pelo biólogo alemão Bertalanffy em 1951, o modelo de sistema aberto passa a ser aplicado na teoria organizacional a partir de sua leitura pelo funcionalismo de Parsons (apud MOTTA; VASCONCELOS, 2010). Por ideias centrais da abordagem sistêmica das organizações: $o$ homem funcional, conflitos, apenas de papéis e os incentivos mistos. A adaptação constante da organização ao meio ambiente é um pressuposto sistêmico. Por extensão, segundo a abordagem contingencial, a organização é dependente do meio ambiente e se modifica segundo as condições cambiantes do seu ambiente externo, que colocam limitações e circunstâncias momentâneas ou duradouras. Esta abordagem introduz uma nova mentalidade aberta e participativa na teoria da administração.

A complexidade, mudanças e incertezas contidas na sociedade implicam o aumento de demandas da administração enquanto atividade humana. A tarefa básica da administração é fazer as coisas através das pessoas. Portanto, basicamente gerir pessoas em cooperação, visando alcançar objetivos com eficiência dos recursos. Para tanto, são desenvolvidos modelos de gestão e estratégias adequadas à solução dos problemas encontrados no mundo organizacional.

Em uma visão neoclássica do pensamento administrativo, com vistas à sua aplicabilidade nas organizações, as ideias básicas dos seus pioneiros são resgatadas na assunção de que a administração seja, em última instância, um processo gestor de planejamento, organização, direção e controle. As expressões do processo administrativo enquanto combinação do planejamento, estruturação organizacional, modos de direção e avaliação constituem modos de gestão. A forma como essas funções gestoras se expressam e seu movimento linear, cíclico ou interativo informam o modelo de gestão vigente em cada organização. A análise de uma organização no seu funcionamento ou a leitura de um texto sobre gestão permite desvelar a fundamentação teórica que lhe sustenta. A interação dinâmica entre as funções gestoras é defendida pela escola neoclássica. Ou, uma gestão autoritária e de controle rígido nos informa um modelo burocrático de organização.

Numa revisão das abordagens contemporâneas das organizações Misoczky e Moraes (2011, p.50) demonstram a atualidade e vigência das formulações weberianas no pensamento estrutural funcionalista identificado em estudos organizacionais. As mesmas autoras lembram que o próprio Weber admitiu a possibilidade de uma administração democrática, com as decisões importantes sendo tomadas em assembleias por todos os membros da organização. Com essas bases as autoras apresentam as práticas organizacionais horizontais, que no senso comum vem sendo traduzidas para o conceito de autogestão. As categorias propostas por Misoczky e Moraes (2011, p.86) para um tipo ideal de práticas organizacionais horizontais consistem em: mandar obedecendo, participação direta, decisões coletivas, delegação autorizada $e$ corresponsabilidade.

Um movimento de diferenciação entre a administração pública e empresarial que possa ter existido em alguns momentos, há dado espaço para o reconhecimento das posições originais da teoria da administração, a exemplo de Fayol e Weber que claramente indicavam a aplicação da teoria das organizações para qualquer esfera. Desde as abordagens acima citadas, pesquisas realizadas por diversos autores da teoria organizacional, com destaque para os de formação mais estruturalista, e após estes os de 
abordagens contingenciais, como também outros autores posteriormente (PETTIGREW, 1992), todos têm reafirmado que a teoria da administração é genérica. Ou seja, aplicável aos mais diversos setores de produção de bens e serviços para a sociedade. As peculiaridades do processo produtivo nos diferentes setores e áreas de produção são equacionadas na aplicação pelo próprio setor, referenciados nas produções pertinentes. Todavia, há que se reconhecer o maior grau de politização e compromisso social pressuposto no setor público como diferencial.

Para a discussão das especificidades do setor público e privado das organizações, destacamos a contribuição de Paula (2005, p.36) ao analisar, em uma perspectiva comparada, a administração pública gerencial e a administração pública societal. Ao examinar os antecedentes e as características desses modelos de gestão pública, a autora compara "os modelos a partir de seis variáveis de observação: a origem, o projeto político, as dimensões estruturais enfatizadas na gestão, a organização administrativa do aparelho do Estado, a abertura das instituições à participação social e a abordagem de gestão".

Finalmente, abordamos alguns dos enfoques teóricos pós-contingencias apresentados por Motta e Vasconcelos (2010): a cultura organizacional e o poder nas organizações.

$\mathrm{Na}$ cultura organizacional, além do aspecto interno e relacional das organizações, metodologicamente reportamo-nos ao âmbito de uma etnografia crítica (MADISON, 2005) que consequentemente implica em análises mais amplas, alguns de seus pressupostos são: enfrentamento da tensão entre familiaridades e estranhamentos, vivendo com e não como os "nativos" tendo outras referências socioculturais; trabalho de campo como encontro etnográfico e prática dialógica; exploração da dimensão política e situação de cooperação e conflito; condição ética da etnografia; possibilidade de inversão de poder entre observado e observador; debate teórico situando o propósito da etnografia; situar o lócus etnografado no sistema econômico e político mundial, mantendo relação dialética com o contexto sócio histórico local, regional, nacional e global; reconstrução histórica do presente etnográfico; passagem do campo ao texto considerando a relação pesquisador-sujeitos-leitores, inclusive com negociação das interpretações construídas com os sujeitos; reconhecer que a interpretação etnográfica consiste num complexo jogo político.

Na perspectiva do Poder nas Organizações, para Foucault (1989), o que faz com que o poder se mantenha e seja aceito nas instituições é simplesmente que ele não pesa só como uma força que diz não, mas que de fato permeia, produz coisas, induz ao prazer, forma saber e produz discurso (EIZIRIK, 2002). Foucault (op cit.) ainda aponta como sistemas de exclusão o trabalho, a família, o discurso, e a posição social possibilitando uma aproximação dos sujeitos sociais.

As práticas desenvolvidas com os graduandos em Saúde Coletiva no âmbito das disciplinas de introdução às teorias organizacionais e de gestão de sistemas e serviços de saúde têm utilizado as teorias organizacionais numa perspectiva mais crítica nas análises de instituições públicas e privadas, propiciando a apreensão e discussão das expressões dos enfoques teóricos nas práticas organizacionais em sistemas e serviços de saúde.

As limitações das abordagens próprias de uma teoria geral da Administração, embora tratadas com rigor científico e explicativo por autores como Motta e Vasconcellos (2010), são insuficientes e não adequadas a formação do profissional Sanitarista. O papel do gestor de um sistema universal de saúde e de proteção dos direitos sociais, que política e paradoxalmente atua no contexto neoliberal do desenvolvimento brasileiro desde a década de 1980 (DRAIBE, 2011; COHN, 2006), implica uma importante aproximação ao pensamento crítico na grade curricular das teorias organizacionais para pautar o aprendizado de uma administração voltada para as transformações sociais e mudanças organizacionais no seu campo de práticas. Para Santos et al. (2009) a gestão como objeto da administração tem o propósito de organizar as relações sociais de produção e distribuição, implicando em esforços intelectuais no campo da administração política, como por exemplo na análise das categorias temporalidade e continuidade administrativa que muito bem se aplica às transformações dos serviços de saúde. 


\section{Discussão}

A partir das reflexões sobre uma sociologia para a administração de Guerreiro Ramos $(1983,1989)$ e do desenvolvimento de uma produção de conhecimentos sobre a realidade da administração brasileira nos últimos anos, adotou-se a inclusão da abordagem crítica perpassando os conteúdos das teorias das organizações explicitando as limitações das abordagens clássicas, neoclássicas e contingenciais, por coerência inclusive com o próprio campo da Saúde Coletiva que se materializa na produção e transformação social.

Para Souza et al. (2004) a maior parte do arcabouço intelectual da Teoria Crítica na Administração é inspirada na Escola de Frankfurt. A aplicação dos seus conceitos elementares nos pareceu imprescindível em contextos locais onde se reproduzem as práticas de saúde e no fortalecimento da gestão democrática das políticas de saúde. Assim, buscamos em tais referências embasar os conteúdos programáticos das teorias organizacionais para a abordagem das discussões sobre: liderança (BERGAMINI, 1994 e SIEVERS, 1997); autogestão (ALBUQUERQUE, 2003), etnografia crítica (MADISON, 2005), práticas organizacionais verticais e horizontais (MISOCZKY e MORAES, 2011), modelos de gestão gerencial e societal (PAULA, 2013) e a perspectiva histórica e multidimensional nas análises das organizações (MARTINS, 2012).

$\mathrm{Na}$ formação acadêmica do profissional Sanitarista buscamos evitar os percursos teóricos que caminharam das estruturas sociais do pensamento crítico às interações da pósmodernidade nas últimas décadas, considerando as entidades mais amplas e os pressupostos de Nunes (2014) de que a construção teórica é convergente e se realiza a partir de encontros interdisciplinares. Neste sentido, para Santos et al. (2009) as organizações podem ser objetos de pesquisa da antropologia, da sociologia, da economia, da medicina, o que, a nosso ver, é indispensável na Saúde Coletiva.

Considerar as organizações como expressão do querer, do saber e do fazer, implica buscar participação, responsabilização e autonomia das diferentes categorias de trabalhadores. Em uma concepção praxeológia as organizações buscam, através da atividade humana, reorientar e organizar as próprias organizações e a sociedade pela ação autônoma dos seres humanos.

Nestes pressupostos, a agonística foucaultiana entre o saber, o poder e o sujeito (FOUCAULT, 1989; EIZIRIK, 2002), já utilizada como referência no campo das políticas públicas no estado (WEISS, 1992), foi reconhecida na fundamentação das teorias organizacionais. Esse olhar pautou outras disciplinas da área de Políticas e Gestão em Saúde quando da criação do Curso de Mestrado em Saúde Coletiva da UFMT em 2003, propiciando a reflexão sobre a dominação que determinados grupos exercem sobre os outros, dentro e fora das organizações, o que se revela importante na conscientização e autorreflexão para a emancipação dos oprimidos como citado por Souza et al. (2004).

Assim, reconhecemos o poder como uma categoria explicativa da realidade. As relações de poder podem ser afetadas pelo pensamento estratégico em saúde segundo Testa (1981, apud GIOVANELLA, 1990, p.142), que, de forma abstrata define poder como a "[...] capacidade possuída por alguém, pessoa, ou grupo [...] de lograr que outro faça algo que este não faria, se aquele não tivesse poder. [...] Poder é a capacidade de uma classe social realizar seus objetivos históricos".

Numa perspectiva histórica e multidimensional das análises das organizações, Martins (2012) contribui com sua noção do espaço dinâmico-organizacional, que incorpora a dimensão temporal. A dinâmica desse espaço organizacional opera a partir do planejamento, da organização e da execução de uma ação cooperativa, cujo objetivo é a razão de existência da própria organização. "[...] lidas historicamente as organizações adquirem memória e assumem diferentes configurações em diferentes momentos de sua existência, configurações estas que se (re) constroem também historicamente" (p.5).

Existe a possibilidade de um salto das organizações para a gestão democrática e participação cidadã. Entre possíveis cenários pós-neoliberais, outros autores como Gallegos (2009) traz a proposta de governança participativa como um modo de efetivar-se a participação cidadã nos processos políticos assegurando o protagonismo de setores excluídos na perspectiva de uma radical transformação social.

As teorias das organizações surgem como uma resposta aos problemas da sociedade mais relevantes de sua época, implicando diferentes abordagens do seu objeto de estudo - a ação organizacional. Reconhecidas as organizações/instituições como detentoras em seu espaço particular dos elementos essenciais que constituem o objeto da disciplina administração, a essência desse objeto para a 
administração política "perpassa o espectro das relações sociais internas das organizações e se estabelece nos limites das relações sociais mais amplas; portanto no âmbito da sociedade" (SANTOS, RIBEIRO, SANTOS, 2009, p.930).

\section{Considerações Finais}

Fundamentado em conceitos como dialética, materialismo histórico, sistemas cooperativos e capitalistas, modo de produção, estrutura social, formas de governo, classes sociais e práxis, o conteúdo programático da disciplina produz um avanço nas limitações das abordagens usuais da administração inserindo outros significados como liderança; autogestão, etnografia crítica, práticas organizacionais verticais e horizontais, modelos de gestão gerencial e societal, e a perspectiva histórica e multidimensional nas análises das organizações.

Para além da necessidade de aprofundamento dos estudos, as perspectivas de uma governança participativa (GALLEGOS, 2009) e do modelo de administração pública societal e a abordagem de gestão social (PAULA, 2005) permitem vislumbrar uma nova forma de governança e administração política no campo da Saúde Coletiva.

As experiências de ensino das teorias das organizações no curso de graduação no ISC/UFMT têm permitido o aprofundamento das reflexões sobre a importância do pensamento crítico no fortalecimento dos processos de democratização da gestão das políticas públicas e nas mudanças organizacionais dos serviços de saúde e da própria organização dos serviços públicos.

A utilização de fundamentos do pensamento crítico para as organizações propiciou relevantes experiências de aprendizado e discussões teórico-empíricas com os discentes sobre o campo de conhecimentos e práticas da Saúde Coletiva, em suas expressões na área de Política, Planejamento e Gestão em Saúde.

Em todos os níveis da administração e organização de serviços de saúde pode-se fomentar decisões considerando um maior número de critérios e recursos intelectuais para questionamento de tendências totalitárias (SOUZA et al, 2004), impeditivas das mudanças necessárias ao processo de Reforma Sanitária Brasileira, assim como ao comprometimento com os seus princípios e valores éticos e políticos.

Concluímos esse texto reafirmando a importância da abordagem crítica na formação de Sanitaristas, por coerência com o campo de conhecimentos e práticas da Saúde Coletiva (re) construído epistemologicamente no contexto da Reforma Sanitária Brasileira.

\section{REFERÊNCIAS BIBLIOGRÁFICAS}

AlBUQUerque, P. P. Autogestão. In: CATTANI, A.D.A. (Org.). A Outra Economia. Porto Alegre: Veraz, 2003. p.20-25.

AROUCA, S. O dilema preventivista: contribuição para a compreensão e crítica da Medicina Previdenciária. Rio de Janeiro/São Paulo: Fiocruz/Unesp, 1976.

BERGAMINI, C.W. Liderança: a administração do sentido. RAE, São Paulo. v.34, n.3, mai./jun. 1994.

BOSI, M.L.M.; PAIM, J.S. Graduação em Saúde Coletiva: limites e possibilidades como estratégia de formação profissional. Ciência \& Saúde Coletiva, Rio de Janeiro, v.15, n.4, p.2029-2038. 2010.

BRASIL. Constituição da República Federativa do Brasil. Brasília: Gráfica do Senado, 1988.

CASTELLANOS, M.E.P. et al. Estudantes de graduação em Saúde Coletiva - perfil sóciodemográfico e motivações. Ciência e Saúde Coletiva. Rio de Janeiro, v.18, n.6, p. 1657-1666. jun. 2013. 
CHANLAT, J.F., coordenador. O indivíduo na organização: dimensões esquecidas. 3a ed. v.I, II e III. São Paulo: Atlas, 1996.

COHN, A. O SUS e o direito à saúde: universalização e focalização nas políticas de saúde. In: Lima NT; Gerschman S, Edler FC, Suárez JM (orgs). Saúde e Democracia: história e perspectivas do SUS. Rio de Janeiro: Fiocruz, 2006. p.385-406.

DONNANGELO, M.C.F.; PEREIRA, L. Saúde e sociedade. São Paulo: Duas Cidades, 1976.

DRAIBE, S.M. Uma nova agenda social na América Latina? Pontos de partida para a análise comparada dos sistemas de proteção social e suas mudanças recentes. In: Sola L, Loureiro MR. (orgs.). Democracia, mercado e estado: o B de Brics. São Paulo: FGV, 2011.

EIZIRIK, M. F. Michel Foucault um pensador do presente. Ijuí: UNIJUİ, 2002.

FLEURY, S. Bases Conceituais da Reforma Sanitária. In: FLEURY, S. (Org.) Saúde e democracia: a luta do CEBES. São Paulo: Lemos Editorial, 1997.

FGSC/Abrasco - Fórum da Graduação em Saúde Coletiva / Associação Brasileira de Saúde Coletiva. Diretrizes Curriculares Nacionais (minuta), 2014. Rio de Janeiro: Abrasco, 2015. Disponível em: <http://www.abrasco.org.br/site/wp-content/uploads/2015/06/DCN-CGSC-versao-junho-2015.pdf>. Acesso em: 25 set. 2015.

FOUCAUlT, M. Micro Física do Poder. Biblioteca de Filosofia e História das Ciências. Vol. 7. $9^{\mathrm{a}}$ ed. Rio de Janeiro: Graal, 1989.

GALLEGOS, F.R. Sociedad civil, participación y democracia en el nuevo contexto político latino-americano. In: FLEURY, S.; LOBATO, L.V.C. (Orgs.). Participação, democracia e saúde. Rio de Janeiro: CEBES, 2009. p.47-82.

GIOVANELLA, L. Planejamento Estratégico em Saúde: Uma Discussão da Abordagem de Mário Testa. Cad. Saúde Pública, Rio de Janeiro, 1999. v.6, n.2, p.129-153, abr./jun. 1990.

GRAMSCI, A. Os Intelectuais e a Organização da Cultura. $4^{\mathrm{a}}$ ed. São Paulo: Civilização Brasileira, 1982.

GRAHAM, P.(org.). Mary Parker Follet: profeta do gerenciamento. Rio de Janeiro: Qualitymark, 1997.

ISC/UFMT. Projeto Pedagógico do Curso de Graduação em Saúde Coletiva. Cuiabá: UFMT, 2010.

KEHRIG, R.T. Integralidade da Atenção à Saúde: suas expressões na organização tecnológica do trabalho em serviços locais de saúde. [tese de Doutorado em Saúde Pública]. Faculdade em Saúde Pública. São Paulo: Universidade de São Paulo, 2001.

KEHRIG, R.T.; MARTINELLI, N.L.; SPINELLI, M.A.S.; GUGILMIN, S.A.; SCATENA, J.H.G. Aproximações à institucionalidade, governança e gestão na regionalização da saúde. (Cap.2). In: SCATENA, J.H.G.; KEHRIG, R.T.; SPINELLI, M.A.S. Regiões de Saúde: diversidade e processo de regionalização em Mato Grosso. São Paulo: Hucitec, 2014. p.47-83.

KINCHELOE, J.L.; MCLAREN, P. Repensando a teoria crítica e a pesquisa qualitativa. (Cap.10). In: DENZIN, N.K.; LINCOLN, Y.S. et al. O planejamento da pesquisa qualitativa: teorias e abordagens. $2^{\mathrm{a}}$ ed., $1^{\mathrm{a}}$ reimp. Porto Alegre: Artmed, 2007.

MADISON, D.S. Critical Ethnography: Method, Ethics, and Performance. Thousand Oaks; London; New Delhi: Sage Publications, 2005.

MARTINS, P.E.M. O espaço-dinâmica organizacional em perspectiva histórica. In: VIEIRA, H. C. et al. (Orgs.) Brasil Holândes: História, Memória e Patrimônio Compartilhado. São Paulo: Alameda, 2012, p.323-338.

MATUS, C. Política, Planificação e Governo. Brasília: IPEA, 1993.

MENDES-GONÇALVES, R.B. Processo de trabalho em saúde. Cadernos CEFOR. São

Paulo: Secretaria Municipal de Saúde, 1992.

MINTZBERG, H.; AHLSTRAND, B.; LAMPEL, J. Safári de estratégia: um roteiro pela selva do planejamento estratégico. Porto Alegre: Bookman, 2000.

MINTZBERG, H.; LAMPEL, J.; QUINN, J.B.; GHOSHAL, S. O processo da estratégia:

conceitos, contextos e casos selecionados. Porto Alegre: Bookman, 2006.

MISOCZKY, M.C. O campo da atenção à saúde após a Constituição de 1988: uma narrativa de sua produção social. Porto Alegre: DaCasa, 2002. 
MISOCZKY, M.C. Avaliação das estratégicas locorregionais de articulação entre os níveis de cuidado à saúde: estudo de múltiplos casos nos estados do Rio Grande do Sul, Mato Grosso e Pernambuco. Projeto de Pesquisa (CNPq). Porto Alegre: UFRGS, 2005.

MISOCZKY, M.C.; MORAES, J. Práticas Organizacionais em Escolas de Movimentos Sociais. Porto Alegre: DaCasa Editora, 2011.

MORGAN, G. Imagens da organização. São Paulo: Atlas, 1996.

MOTTA, F.C.P. Participação e co-gestão. $2^{a}$ ed. São Paulo: Brasiliense, 1984.

MOTTA, F.C.P.; VASCONCELOS, Isabella F.G. Teoria Geral da Administração. $3^{a}$ ed. revista. São Paulo: Cengage Learning, 2010.

MOURA, Tânia Maria de Melo Aproximações entre as ideias de Freire e Vygotsky: importância para a prática pedagógica com jovens e adultos. Disponível em:

http://www.paulofreire.ufpb.br/paulofreire/Files/seminarios/oral04.pdf < acessado em set 2015>

NUNES, Everardo D. A. Construção teórica na Sociologia da Saúde: uma reflexão sobre sua trajetória. Ciência e Saúde Coletiva. Rio de Janeiro, Vol. 19, N. 4, abril 2014.

PAIM, J.S.; ALMEIDA Fº N. Saúde Coletiva: campo científico e âmbito de práticas. In: A crise da Saúde Pública e a utopia da Saúde Coletiva. Salvador: Casa da Qualidade, 2000. (Cap. 4), p.59-71.

PAIM, J. Reforma Sanitária Brasileira: contribuição para a compreensão e crítica. Salvador: EDUFBA / Rio de Janeiro: Editora Fiocruz; 2008.

PAULA, Ana Paula Paes de. Administração pública brasileira entre o gerencialismo e a gestão social. RAE, São Paulo. V. 45. N.1, 2005.

PETTIGREW, A. The character and significance of strategy process research Strategic Management Journal, v.13, p.5$16,1992$.

PINCHOT, G.; PINCHOT, E. O poder das pessoas. Rio de Janeiro: Campus, 1995.

RAMOS, Guerreiro. Administração e Contexto Brasileiro. Biblioteca de Administração Pública - 12. 2a . ed. Rio de Janeiro: FGV, 1983.

A nova ciência das organizações: uma reconceitualização da riqueza das nações. 2. ed. Rio de Janeiro : FGV, 1989.

SANTOS, R. S.; RIBEIRO, E. M.; SANTOS, T. C. S. Bases Teórico-metodológicas da Administração política. Rev.Adm.Pública, Rio de Janeiro, v.43, n.4. p.919-41, julago, 2009.

SENGE, P.M. A quinta disciplina: arte e prática da organização que aprende. $6^{\text {a }}$ ed. São Paulo: Best Seller - Círculo do Livro, 2000.

SHON, D.A. Beyond the stable state. New York : The Norton Library, 1971.

SIEVERS, B. Liderança como perpetuação da imaturidade. Revista de Negócios. Blumenau, v.2, n.3. abril-junho. 1997. Disponível em: <http://proxy.furb.br/ojs/index.php/rn/article/view/518/470 >. Acesso em 9 jul. 2013.

SOUZA, P.R.B.; SALDANHA, A.N.K.; ICHIKAWA, E.Y. Teoria Crítica na Administração. Caderno de Pesquisa em Administração, São Paulo, v.1, nº 3, p. 1-9, jul-set. 2004.

TEIXEIRA C.F., ABREU DE JESUS W.L., SOUZA M.K.B, ROCHA M.N.D. Produção científica sobre Política, Planejamento e Gestão em Saúde no Campo da Saúde Coletiva: visão panorâmica. (Capítulo 3). In: Paim JS, Almeida-Filho N. (orgs.) Saúde Coletiva: teoria e prática. Rio de Janeiro: MedBook, 2014. (p.585-594).

TESTA, M. Análisis de instituciones hipercomplejas. In: MERHY, E.E.; ONOCKO, R. Agir em Saúde: um desafio para o público. São Paulo: Hucitec, 1997. p.17-70.

URIBE RIVERA, F.J. Análisis estratégico em salud y gestión a través de la escucha. Rio de Janeiro: Fiocruz, 2006. 
WEISS, M.C.V. Nutrição e Condições sócio-biológicas nos assentamentos em Mato Grosso. Dissertação (Mestrado em Sociologia) Instituto de Filosofia e Ciências Sociais da Universidade Federal do Rio Grande do Sul. Porto Alegre, 1993.

WEISS, M.C.V.; BORDIN, R. (Org.). Estratégias de atenção à saúde no Distrito Sanitário Especial Indígena de Cuiabá. Porto Alegre: DaCasa, 2013.

WEBER, M. Os fundamentos da organização burocrática. In: CAMPOS, E. Sociologia da burocracia. $4^{\mathrm{a}}$ ed. Rio de Janeiro: Zahar, 1978. p.15-28. 